
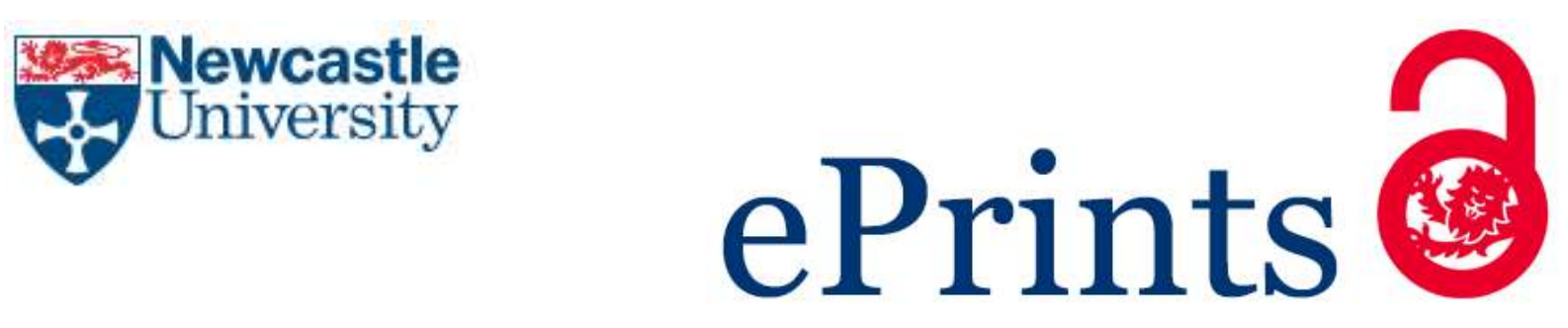

Al-Musawi M, Durham J, Whitworth JM, Stone SJ, Nixdorf DR, Valentine RA. Effect of topical neuromodulatory medications on oral and skin keratinocytes. Journal of Oral Pathology and Medicine 2017, 46(2), 134-141.

\title{
Copyright:
}

This is the peer reviewed version of the following article: Al-Musawi M, Durham J, Whitworth JM, Stone SJ, Nixdorf DR, Valentine RA. Effect of topical neuromodulatory medications on oral and skin keratinocytes. Journal of Oral Pathology and Medicine 2017, 46(2), 134-141., which has been published in final form at [Link to final article using the DOI]. This article may be used for non-commercial purposes in accordance with Wiley Terms and Conditions for Self-Archiving.

DOI link to article:

http://dx.doi.org/10.1111/jop.12437

Date deposited:

$06 / 03 / 2018$ 


\title{
Title Page
}

\section{Effect of Topical Neuromodulatory Medications on Oral and Skin}

\author{
Keratinocytes
}

Mustafa Al-Musawi ${ }^{1}$, Justin Durham ${ }^{1,2}$, John M. Whitworth ${ }^{1}$, Simon J. Stone ${ }^{1}$, Donal R. Nixdorf ${ }^{3,4,5}$, and Ruth A. Valentine ${ }^{1,6}$

${ }^{1}$ Centre for Oral Health Research, School of Dental Sciences, Newcastle University, Newcastle upon Tyne, UK.

2 Institute of Health and Society, Newcastle University, Newcastle upon Tyne, UK.

3 Division of TMD and Orofacial Pain, School of Dentistry, University of Minnesota, Minneapolis, MN, USA.

4 Department of Neurology, Medical School, University of Minnesota, Minneapolis, MN, USA.

${ }^{5}$ HealthPartners Institute for Education and Research, Bloomington, MN, USA

${ }^{6}$ Human Nutrition Research Centre, Newcastle University, Newcastle upon Tyne, UK.

Corresponding author: J. Durham (justin.durham@newcastle.ac.uk)

School of Dental Sciences

Newcastle University

Framlington Place

Newcastle upon Tyne

NE2 4BW

UK

Telephone: +44(0) 1912088347

Fax: +44 (0) 1912086137

Key words: Amitriptyline, Carbamazepine, Gabapentin, Orofacial pain, Neuropathic pain

Running Title: Safety of Topical Neuromodulatory Drugs 


\section{Abstract}

Background

Neuromodulatory medications (NMs), such as Amitriptyline, Carbamazepine, and Gabapentin are used as topical preparations for management of neuropathic orofacial pain (NOP) and have produced promising preliminary results. The aim of this study was to investigate the effects of three aforementioned NMs on cell lines relevant to the orofacial tissues in vitro as no published studies have examined the effect of these topical NMs.

\section{Methods}

Cellular viability was measured using alamarBlue ${ }^{\circledR}$, testing cumulative and specific time-point effects of NMs on human skin keratinocytes and oral keratinocytes. Effects of the NMs on cell counts were investigated by CCK-8 assay. Drug concentrations released from NM orabase pastes after 30 min incubation were measured by High-Performance Liquid Chromatography. Using these clinical concentrations, morphological changes and cytokine expression were investigated using Scanning Electron Microscopy (SEM) and Human Inflammatory Antibody Array $(\mathrm{AAH})$ respectively.

Results

Cumulative and specific time-point viability and cell count methods revealed that Amitriptyline caused a significant decrease in cellular viability and counts in both cell lines. Carbamazepine also had significant effects after long-term exposure and at higher concentrations, whilst Gabapentin had little demonstrable effect. SEM confirmed the cytotoxicity of Amitriptyline, whilst $\mathrm{AAH}$ revealed no significant changes in cytokine expression following Amitriptyline, Carbamazepine or Gabapentin exposure compared with control.

Conclusions

The results raise concerns about the safety of topical Amitriptyline as it was cytotoxic to skin and oral keratinocytes in both exposure-times and concentrations, whilst Carbamazepine was cytotoxic only at high concentrations and after longer exposuretimes and Gabapentin had no demonstrable effects. 


\section{Introduction}

Orofacial pain (OFP) is "pain perceived in the face and/or oral cavity caused by diseases or disorders of regional structures, by dysfunction of the nervous system, or through referral from distant sources" (1). The pathophysiology of persistent OFP is varied, but includes neuropathy (2) which can be due to macro or microscopic trauma, a disorder, or a disease affecting the trigeminal nerve (3). There are several persistent OFP conditions thought to be of neuropathic origin including Persistent Dento-Alveolar Pain disorder (PDAP) and Trigeminal Neuralgia $(4,5)$. Neuropathic pain affecting the trigeminal region is known to exert significant impacts on individual's daily lives (6) and following root canal treatment or extraction PDAP is thought to occur in $1.6 \%$ (7) of cases while trigeminal neuralgia is thought to occur in 12.7 per 100,000 people (8).

Contemporary evidence-based management of neuropathic pain suggests sequential phases of treatment according to the primary diagnosis, efficacy, and side effect profile of the medication(s) employed (9). Core classes of medications recommended for their efficacy in neuropathic (orofacial) pain are antidepressants and anticonvulsants with evidence of their efficacy largely being derived from studies focussing on neuropathic pain elsewhere in the body (10). Management of neuropathic OFP follows this evidence base, but one of the disadvantages of this approach is the necessity to deliver medication, such as antidepressants and anticonvulsants, systemically. This route of administration has concomitant side effects that are known to affect patient's adherence to drug regimens especially in neuropathic OFP (6). As opposed to systemic administration, topical administration of medication may help improve drug delivery to the site of need and also the sideeffect profile of the medication; thereby potentially improving adherence to and efficacy of therapy (11). This approach has already shown promise in neuropathies outside the orofacial region using medications, such as capsaicin and lignocaine patches (12). Sporadic reports of clinical experience employing compounded, topical, forms of antidepressants and anticonvulsants (neuromodulatory medication [NM]) in neuropathic OFP have emerged in the literature with largely promising results $(13,14)$. The analgesic effect of NMs attributed to peripheral targets, Amitriptyline has a blocking effect on ion gated channels $\left(\mathrm{Na}^{+}, \mathrm{Ca}^{++}\right.$and $\mathrm{K}^{+}$ 
channels), along with NMDA-receptors and modification of adenosine-receptors functions (15-17). Carbamazepine and Gabapentin affinity to block sodium channels and calcium subunit ( $\alpha 2 \delta-1)$ respectively made them as adjunctive analgesics in chronic pain conditions topically, and systemically $(15,18)$.

While hepatic, renal, and neuronal tissue cytotoxicity testing has been conducted for the systemic administration of NMs, there are no such data for their topical application to orofacial tissues or thoroughly investigation of the inflammatory profile including cytokine expression except clinical notes (19) following topical application. The effect of NMs exposure on cytokine expression has been investigated following systemic administration and in vitro studies. The exposure or treatment was generally found to be associated with suppression of specific pro-inflammatory cytokines (IL-1 $\beta$ and TNF- $\alpha$ ), in addition to over expression of anti-inflammatory cytokine (IL-10). Carbamazepine exposure and treatment was associated with the over expression of the following groups of cytokines: IL-2, IL-5, IL-6 and IL-10 (2025) .

This study investigates the effects of three NMs (Amitriptyline, Carbamazepine and Gabapentin) on the relevant oral and skin cell-line models and provides preliminary data on drug release from common compounded formulations of these drugs in vitro.

\section{Materials and Methods}

Four groups of experiments were conducted as part of this paper:

1) Cell viability and median lethal dose calculations.

2) Cell count experiments.

3) Drug release and cellular morphology experiments.

4) Cytokine expression experiments.

The NMs included and their concentrations were decided after a literature search $(13,14)$, and an informal survey of the international members of the University of California, Los Angeles (UCLA) OFP list-serve about the more common compounded medications used in neuropathic OFP. The only exceptions to this were the cellular morphology and cytokine expression experiments, which used concentrations determined from the drug release experiment. 
Keratinocyte non-cancer cell lines were utilised in this study as representative of the target orofacial tissues for topical NMs. For more comparative reproducible results, the use of cell lines has been approved in cytotoxicity and dental biocompatibility investigations $(26,27)$. The cell lines employed were: immortalized skin keratinocytes (HaCat) (28) and immortalized keratinocyte cell line (OKF6-TERT1) from oral mucosa (29).

\section{Preparation of drug solutions}

Pure Amitriptyline hydrochloride (AMI), Carbamazepine (CBZ) and Gabapentin (GAB) were obtained from Sigma-Aldrich, UK. Amitriptyline and Gabapentin were dissolved in sterile deionized water to stock concentrations of $63.7 \mathrm{mM}$ and $29.1 \mathrm{mM}$ respectively, before further dilution in fresh culture media to the working concentrations of $200 \mu \mathrm{M}$ and $1.8 \mathrm{mM}$, and $150 \mu \mathrm{M}$ and $5.54 \mathrm{mM}$ respectively. Carbamazepine was dissolved in $100 \%$ ethanol to a stock concentration of $84.6 \mathrm{mM}$ before further dilution in fresh culture medium to two final working solutions of $100 \mu \mathrm{M}$ and $1.7 \mathrm{mM}$ (Table 1, outlines the equivalent clinical concentrations of these laboratory values). The final concentration of ethanol was $<2 \%$ in the final working solutions and this concentration of ethanol alone did not affect the viability of any cell line. For antibody array experiments, serum free media were used to prepare the drug solutions.

\section{Cell Culture}

Immortalized HaCat cells (passage 67) and OKF6-TERT1 cells (passage 7) were maintained and passaged as described previously $(29,30)$.

\section{Cellular viability and medial lethal dose:}

AlamarBlue $^{\circledR}$ (AbD Serotec, Oxford, UK) was used to investigate the effect of NMs on cell viability in vitro. This test works by measuring the colour change from blue to pink as a result of Resazurin's chemical reduction, in response to cellular metabolic activities during cellular growth and multiplication. This colour change was measured by absorbance at a wavelength of $570 / 600 \mathrm{~nm}$.

Experiments examined the: (a) cumulative effect of NMs on cellular viability, and (b) the effect of NMs observed at specific time points of cellular exposure.

Median lethal dose (LD50) was calculated using absorbance values obtained by the alamarBlue ${ }^{\circledR}$ method, using semi-log graph paper for all three drugs and for both 
exposure methods (cumulative and specific time points), applying manufacturer instructions.

a: Cumulative NMs effect: HaCat and OKF6-TERT1 cells were seeded at densities of $1 \times 10^{4}$ and $2 \times 10^{4}$ cells/well respectively, in 96-well plates with fresh culture media to a final volume of $200 \mu \mathrm{l}$ per well. Cells were incubated at $37^{\circ} \mathrm{C}$ overnight to ensure cell attachment. The media were then replaced with $200 \mu$ l of previously prepared media containing pure drug solution at different concentrations of Amitriptyline, Gabapentin or Carbamazepine in media plus $10 \%$ (v/v) alamarBlueß). After incubation, the absorbance was measured after $30 \mathrm{~min}, 1 \mathrm{~h}, 2 \mathrm{~h}, 4 \mathrm{~h}$ and $24 \mathrm{~h}$ exposure using a plate reader (Synergy HT, BioTek, Winooski, VT) at two wavelengths (570/600)nm.

b: Effect of NMs at specific time points: HaCat and OKF6-TERT1 cells were seeded at densities of $1 \times 10^{4}$ and $2 \times 10^{4}$ cells/well respectively in 96-well plates containing fresh culture media up to a volume of $100 \mu$ l per well. Cells were incubated at $37^{\circ} \mathrm{C}$ overnight before media replacement with $100 \mu \mathrm{l}$ of previously prepared media containing pure drug solution at the different low and high concentrations of Amitriptyline, Gabapentin or Carbamazepine. After incubation for 30min and $24 \mathrm{~h}$ the effects of the NM's effect were stopped by washing the cells in Phosphate Buffed Saline (PBS) before further incubation with $100 \mu \mathrm{l}$ of fresh media, plus $10 \%(\mathrm{v} / \mathrm{v})$ alamarBlue $\AA$. Absorbance was measured after $4 \mathrm{~h}$ incubation.

2. Cell counting assay: The CCK-8 assay (Dojindo Laboratories, Kumamoto, Japan) is based on cellular activity, specifically dehydrogenases and mitochondrial activity, resulting in reduction of Tetrazolium salts (yellow) to Formazan (orange) that can be quantified. The CCK-8 assay was used to investigate changes in cultured cell counts, in response to exposure the NMs. HaCat and OKF6-TERT1 cells were seeded and treated as before alongside a range of control cells seeded at different cell densities to establish a calibration curve. After incubation for $30 \mathrm{~min}$ and $24 \mathrm{~h}$, the effect of the NM was again stopped by washing the cells in PBS. Cells were then incubated with $100 \mu \mathrm{l}$ fresh media plus $10 \%$ (v/v) CCK-8 reagent. Absorbance was measured after incubation for 150min using a plate reader (BioTek, Winooski, VT) at $450 \mathrm{~nm}$ wavelength. 


\section{Drug release and cellular morphology experiments}

A sterile Orabase ${ }^{\circledR}$ paste without additives (ConvaTec, Deeside, UK) was mixed with the required amount of the pure medication powder using a doubling up technique (31) in order to prepare NMs at clinically published concentrations $(13,14)$. Approximately $2 \mathrm{~g}$ from the resultant Amitriptyline (2\% w/v, 63.7mM), Gabapentin $(4 \% \mathrm{w} / \mathrm{v}, 169.3 \mathrm{mM})$ and Carbamazepine $(4 \% \mathrm{w} / \mathrm{v}, 233.6 \mathrm{mM})$ topical paste was then used to coat the inner walls of a 6 well-plate. The wells were then filled with $6 \mathrm{ml}$ of culture medium. Thirty minutes of incubation were used in both the drug release and cellular morphology experiments as it was felt this was a realistic time for a topical medication to be present in the oral cavity once applied to the buccal mucosa. After $30 \mathrm{~min}$ incubation, the media were aspirated and sent for High-Performance Liquid Chromatography (HPLC) analysis to establish the concentration of drug released from the topical paste. Replicate samples were analysed (Cardiff Toxicology Laboratories, Llandough hospital, Penarth, UK).

\section{Cellular morphology}

HaCat and OKF6-TERT1 cells were seeded on coverslips at $1 \times 10^{5}$ and $2 \times 10^{5}$ per well respectively in a 12 well plate with $2 \mathrm{ml}$ of media as the final volume per well. After overnight incubation, the media were discarded and replaced with $2 \mathrm{ml}$ of new media alone (control) or media containing one of the NMs at a concentration that reflected the HPLC findings in the drug release experiment. After 30min incubation, media were then aspirated and stored at $-20^{\circ} \mathrm{C}$ to be used later in Antibody Array Assay. The cover slips were fixed and processed for SEM as described previously (32).

\section{Cytokine expression}

An exploratory Human Inflammation Antibody Array C1 (RayBiotech ${ }^{\circledR}$, Norcross, USA) was used to investigate a number of cytokines expressed in duplicate samples of conditioned media that had been collected from cells exposed to NMs for 30min. The cytokines present on the array were Eotaxin-1, Eotaxin-2, G-CSF, GM-CSF, IFN- $\gamma$, IL-1 $\alpha$, IL1- $\beta$, IL-2, IL-3, IL-4, IL-6, IL-7, IL-8, IL-10, IL-11, IL-12p40, IL-12p70, IL-13, I-309, TIMP-2. Membranes were treated following the manufacturer's instructions before being developed on highly sensitive Amersham Hyperfilm ECL for 2 min. 
Statistical analysis: Simple descriptive statistics and one-way ANOVA followed by Bonferroni post hoc tests were conducted in SPSS version 22 (SPSS Inc., Chicago, IL).

\section{Results}

\section{Cell Viability}

A: Cumulative NMs effect: In vitro effects of pure NMs on HaCat cellular viability are shown in Figure 1. HaCat cellular viability was significantly reduced by both low $(200 \mu \mathrm{M})$ and high $(1.8 \mathrm{mM})$ Amitriptyline concentrations compared to untreated controls $(p<0.05)$. Carbamazepine exposure significantly reduced cellular viability only at high $(1.7 \mathrm{mM})$ concentrations and after $2 \mathrm{~h}$ of exposure $(\mathrm{p}<0.05)$, while Gabapentin significant reduced viability only at high $(5.54 \mathrm{mM})$ concentrations $(p<0.05)$. HaCat cell exposure to low concentrations of Carbamazepine and Gabapentin at all time points produced no significant changes compared with controls $(p>0.05)$.

In oral keratinocyte cells, (OKF6-TERT1, Figure 2) significant reductions in viability $(p<0.05)$ were observed after exposure to Amitriptyline at low $(200 \mu \mathrm{M})$ concentrations for $4 \mathrm{~h}$ and high $(1.8 \mathrm{mM})$ concentrations for $2 \mathrm{~h}$. Similar observations were found for Carbamazepine after exposure to high $(1.7 \mathrm{mM})$ concentrations for $4 \mathrm{~h}$. Neither concentration of Gabapentin significantly affected cellular viability compared with controls $(p>0.05)$.

The median lethal dose ( $\mathrm{LD}_{50}$ ) of Amitriptyline in HaCat cells (Figure S1, in the supplementary materials) was $512 \mu \mathrm{M}$ and $186 \mu \mathrm{M}$ at $30 \mathrm{~min}$ and $24 \mathrm{~h}$ respectively. For Carbamazepine, the $\mathrm{LD}_{50}$ value for HaCat cells was $398 \mu \mathrm{M}$ after $24 \mathrm{~h}$ exposure (Figure S2). Gabapentin had no LD50 effect (Figure S3). In OKF6-TERT1 cells, the only $L_{50}$ for Amitriptyline was $630 \mu \mathrm{M}$ after $24 \mathrm{~h}$ exposure.

b: Effect of NMs at specific time points: Exposure of HaCat cells to $200 \mu \mathrm{M}$ and $1.8 \mathrm{mM}$ Amitriptyline for $30 \mathrm{~min}$ and $24 \mathrm{~h}$ significantly reduced their viability compared with controls $(p<0.05)$. Exposure to high concentrations of Carbamazepine $(1.7 \mathrm{mM})$ for $24 \mathrm{~h}$ also resulted in a significant loss of viability $(p<0.05)$ (Figure 3$)$. Gabapentin showed no significant effect on cellular viability compared with control. 
Short-term (30 min) exposure of OKF6-TERT1 cells to Amitriptyline, Carbamazepine and Gabapentin at all concentrations significantly decreased cellular viability compared with untreated controls $(p<0.05$, Figure 4). Both Amitriptyline concentrations and high concentrations of Carbamazepine and Gabapentin significantly reduced the viability of OKF6-TERT1 cells after longer exposure (24h), $(p<0.05$, Figure 4).

The only $\mathrm{LD}_{50}$ value was for Amitriptyline exposure at 30min $(141 \mu \mathrm{M})$, (Figures S4S6).

\section{Cell counting assay:}

Using the calibration curve the estimated number of HaCat cells was less than 5,000 after 30min exposure to Amitriptyline at low $(200 \mu \mathrm{M})$ and high $(1.8 \mathrm{mM})$ concentrations. At the $24 \mathrm{~h}$ time point, the cell count was less than 1,000 (Figure S7). Exposure to low $(100 \mu \mathrm{M})$ and high $(1.7 \mathrm{mM})$ concentrations of Carbamazepine for 30 min caused a similar reduction in cell counts. However, after $24 \mathrm{~h}$ exposure to $100 \mu \mathrm{M}$ Carbamazepine, cell counts were similar to controls. High concentration Carbamazepine reduced cell counts to less than 1000 (Figure S8). Gabapentin exposure for 30 mins had no significant effects on cell counts, but after $24 \mathrm{~h}$ exposure to $150 \mu \mathrm{M}$ Gabapentin, cell counts were less than 10,000 (Figure S9).

In OKF6-TERT1 cells, exposure to low concentration Amitriptyline (200 $\mu \mathrm{M})$ for 30 min reduced cell counts by half, to 10,000 (Figure S10). High concentration Amitriptyline $(1.8 \mathrm{mM})$ reduced the cell count to $<2,000$ after 30 mins, whilst after exposure to high and low concentrations for $24 \mathrm{~h}$ cell counts reduced to less than 200.

Exposure to Carbamazepine at both low $(150 \mu \mathrm{M})$ and high $(1.7 \mathrm{mM})$ concentration for $30 \mathrm{~min}$ had no effects on cell counts. After $24 \mathrm{~h}$ exposure to both concentrations, cell counts dropped to 15,000 (Figure S11). Exposure to Gabapentin at low (150 $\mu \mathrm{M})$ and high $(5.45 \mathrm{mM})$ concentrations for $30 \mathrm{~min}$ or $24 \mathrm{~h}$ had no effects on cell counts (Figure S12).

\section{Drug release experiment and cellular morphology experiments}

HPLC analysis of the aspirated media after 30min incubation with Orabase paste containing Amitriptyline ( $2 \%$ w/v), Carbamazepine (4\% w/v), and Gabapentin (4\% 
$\mathrm{w} / \mathrm{v})$, demonstrated transfer of $226 \mu \mathrm{M}, 123.9 \mu \mathrm{M}$ and $5.54 \mathrm{mM}$ drug concentrations respectively in the media.

SEM revealed considerable changes in the cellular attachment and morphology of

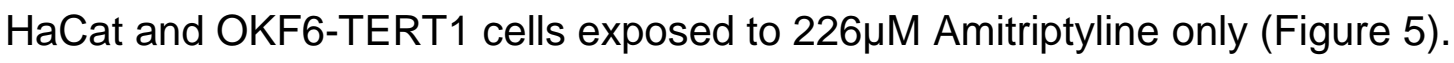

\section{Global cytokine expression}

There were no significant differences in the expression of twenty different inflammatory cytokines between controls and both cell lines after $30 \mathrm{~min}$ exposure to the NMs at the concentrations determined by the drug release experiment. 


\section{Discussion}

Neuropathic OFP can be challenging to manage because of the limited number of proven interventions available (33). This difficulty and patient frustration with side effects (6) may have driven the move towards topical compounded NMs, based upon a reasonable hypothesis about the advantages this route of administration may offer (34). However, compounded formulations are not without their problems (35) and represent a challenge and a responsibility to the prescriber from a safety and efficacy perspective (36).

Prior to commencing any Phase I clinical trial for a new drug, the U.S. Food and Drug Administration (FDA) requires detailed preclinical data for that drug that includes cytotoxicity (37). In these in vitro cytotoxicity studies, the typical tissue regarding systemically administered drugs are target, metabolism and excretion tissues. In the case of topical NMs that are applied on orofacial tissues in higher concentrations, however these drugs are already approved systemic medications, it is necessary to examine their toxic effects on these tissues as changing the rout of administration suggested different pharmacokinetic and pharmacodynamics reactions(38).

This in vitro study tested the effect of three NMs on cellular viability, count and morphology in addition to inflammatory response. Regarding viability, two exposure methods were used: cumulative drug and specific time-point effects.

There are limited reports in the literature regarding the in vitro cytotoxicity of Amitriptyline, but those that are present demonstrate cytotoxicity in both human and animal cell lines attributed to different mechanisms including: mitochondrial dysfunction; increased production of reactive oxygen species leading to alteration in cellular metabolism and permeability and elevated intracellular oxidative stress (25, 39). In the current study, Amitriptyline reduced cellular viability and cell counts in both cell lines at all concentrations and all time points and SEM examination confirmed these findings. The cytotoxicity of Amitriptyline was also demonstrated in its $L D_{50}$ values, which were low in both cell lines and after short exposure times. The apoptotic and anti-proliferative effects of Carbamazepine have been investigated mainly in neurone and glial cell culture, using much lower concentrations than presented here $(40,41)$. Comparing to Amitriptyline, in the current study, Carbamazepine was less cytotoxic in both cell lines, and major 
changes in viability only occurred at high concentrations and longer exposure times. SEM revealed no major changes in cellular morphology and attachment. The LD50 values were also confirmatory as they were calculable only after a cumulative exposure of $24 \mathrm{~h}$, which is not clinically realistic for the topical application of a gel in the oral cavity.

Gabapentin appeared to be the least cytotoxic of the agents tested. Only a high concentration and long exposure time $(24 \mathrm{~h})$ caused a demonstrable reduction in cellular viability. A LD50 was not calculable. This is consistent with previous few reports in literature (42), that employed lower concentrations of Gabapentin in vitro than the current study.

In our experiments, there was a very low level of detected cytokine expression, with all NMs, and the cytokine expressions did not differ to control. This could be due to the short exposure time $(30 \mathrm{~min})$ used and the method of measuring cytokine expression was employed, because it allowed multiple cytokines to be analysed at the same time.

The major limitation of this study is its use of a monolayer culture, which is conceivably more susceptible to the cytotoxic effects of medications than a more complex three-dimensional tissue model. However, the laboratory concentrations of NMs used in viability and counting experiments were much lower than those used in clinical practice and yet still demonstrated cytotoxicity. The concentrations employed also mirrored the ranges of drug concentrations used in the drug release experiment. Within the limits of this investigation, the clinical implications for future topical in vivo NM trials are that low Gabapentin and Carbamazepine concentrations are unlikely to adversely affect oral mucosa and skin. However, if Amitriptyline is to be trialled in vivo, short exposure times and very low concentrations with careful clinical assessment of skin and oral mucosa after repeated exposure are advisable.

\section{Conclusions}

Viability, cell counting, and SEM experiments revealed that Amitriptyline was cytotoxic to both oral and skin keratinocyte cells in vitro. Gabapentin and Carbamazepine affected cellular viability to a lesser extent, even at high concentrations and long exposures. Caution should be exercised in the topical application of Amitriptyline to skin and oral mucosa. 


\section{Acknowledgment}

The authors thank Bob Tomlinson (Huddersfield Pharmacy Specials Calderdale \& Huddersfield NHS Foundation Trust, Huddersfield, UK) for the pharmaceutical advice. This study is funded by the Higher Committee for Education Development in Iraq (HCED) as a part of PhD scholarship in Oral Medicine in the School of Dental Sciences, Newcastle University, United Kingdom. The authors declare no potential conflicts of interest with respect to the authorship and/or publication of this article.

\section{Conflict of interest}

Authors declare no conflict of interest. 


\section{References}

1. IASP. Global year against orofacial pain. 2014 [cited 2015 May 2015]; Available from: http://www.iasp-

pain.org/files/Content/ContentFolders/GlobalYearAgainstPain2/201320140rofacialPain/Fac tSheets/Orofacial Pain.pdf

2. de Leeuw R. Orofacial pain: guidelines for assessment, diagnosis, and management. 4th ed. London: Quintessence, 2008; 2008.

3. Merskey H, Bogduk N. Classification of Chronic Pain. IASP Taxonomy

2012 22/5/2012 [cited 2015 4/05/2015]; Second Edition, revised:[Available from: http://www.iasp-pain.org/Taxonomy?navltemNumber=576\#Neuropathicpain

4. Zakrzewska JM, McMillan R. Trigeminal neuralgia: The diagnosis and management of this excruciating and poorly understood facial pain. Postgraduate Medical Journal 2011;87(1028):410-16.

5. Baad-Hansen L. Atypical odontalgia - pathophysiology and clinical management. Journal of Oral Rehabilitation 2008;35(1):1-11.

6. Durham J, Nixdorf DR. Healthcare pathway and biopsychosocial impact of persistent dentoalveolar pain disorder: a qualitative study. International Endodontic Journal 2014;47(12):1151-59.

7. Nixdorf D, Moana-Filho E. Persistent Dento-Alveolar Pain Disorder (PDAP): Working towards a Better Understanding. Reviews in Pain 2011;5(4):18-27.

8. Koopman JSHA, Dieleman JP, Huygen FJ, de Mos M, Martin CGM, Sturkenboom MCJM. Incidence of facial pain in the general population. Pain 2009;147(1-3):122-27.

9. NICE. the pharmacological managment of neuropathic pain in adults in non-specialist settings. 2013 [cited 2015 June 2015]; Available from:

http://www.nice.org.uk/guidance/cg173

10. Sauzet $\mathrm{O}$, Williams JE, Ross J, et al. The characteristics and quality of randomized controlled trials in neuropathic pain: A descriptive study based on a systematic review. Clinical Journal of Pain 2013;29(7):591-99.

11. Jorge LL, Feres CC, Teles VEP. Topical preparations for pain relief: Efficacy and patient adherence. Journal of Pain Research 2011;4:11-24.

12. Attal N, Cruccu G, Baron R, et al. EFNS guidelines on the pharmacological treatment of neuropathic pain: 2010 revision. European Journal of Neurology 2010;17(9):1113-23.

13. Padilla M, Clark GT, Merrill RL. Topical medications for orofacial neuropathic pain: a review. The Journal of the American Dental Association 2000;131(2):184-95.

14. Heir G, Karolchek S, Kalladka M, et al. Use of topical medication in orofacial neuropathic pain: a retrospective study. Oral Surgery, Oral Medicine, Oral Pathology, Oral Radiology, and Endodontology 2008;105(4):466-69. 
15. Cummins TR. Voltage gated sodium channels in peripheral nociceptive neurons as targets for the treatment of pain. In: Cairns BE, editor. Peripheral receptors targets for analgesia. First edition. Hoboken, New Jersey: John Wiley and Sons, Inc.; 2009. p. 43-93.

16. Sawynok J, Reid AR, Esser MJ. Peripheral antinociceptive action of amitriptyline in the rat formalin test: Involvement of adenosine. Pain 1999;80(1-2):45-55.

17. Sawynok J. Adenosine receptors. In: Cairns BE, editor. Peripheral receptors targets for analgesia. First edition ed. Hoboken, New Jersey: John Wiley and Sons, Inc.; 2009. p. 24375.

18. Luo ZD, Calcutt NA, Higuera ES, et al. Injury type-specific calcium channel $\alpha 2 \delta-1$ subunit up-regulation in rat neuropathic pain models correlates with antiallodynic effects of gabapentin. Journal of Pharmacology and Experimental Therapeutics 2002;303(3):1199-205.

19. Dualé C, Daveau J, Cardot JM, Boyer-Grand A, Schoeffler P, Dubray C. Cutaneous amitriptyline in human volunteers: Differential effects on the components of sensory information. Anesthesiology 2008;108(4):714-21.

20. Obuchowicz E, Kowalski J, Labuzek K, Krysiak R, Pendzich J, Herman ZS. Amitriptyline and nortriptyline inhibit interleukin-1 $\beta$ and tumour necrosis factor- $\alpha$ release by rat mixed glial and microglial cell cultures. International Journal of Neuropsychopharmacology 2006;9(1):27-35.

21. Hashioka S, Klegeris A, Monji A, et al. Antidepressants inhibit interferon- $\gamma$-induced microglial production of IL-6 and nitric oxide. Experimental Neurology 2007;206(1):33-42.

22. Backonja M-M, Serra J. Pharmacologic Management Part 1: Better-Studied Neuropathic Pain Diseases. Pain Medicine 2004;5:S28-S47.

23. Mathieu O, Picot MC, Gelisse P, Breton H, Demoly P, Hillaire-Buys D. Effects of carbamazepine and metabolites on IL-2, IL-5, IL-6, IL-10 and IFN- $\gamma$ secretion in epileptic patients: The influence of co-medication. Pharmacological Reports 2011;63(1):86-94.

24. Lee BS, Jun IG, Kim SH, Park JY. Intrathecal gabapentin increases interleukin-10 expression and inhibits pro-inflammatory cytokine in a rat model of neuropathic pain. Journal of Korean Medical Science 2013;28(2):308-14.

25. Moreno-Fernández AM, Cordero MD, de Miguel M, Delgado-Rufino MD, SánchezAlcázar JA, Navas P. Cytotoxic effects of amitriptyline in human fibroblasts. Toxicology 2008;243(1-2):51-58.

26. Ch. BS EN ISO 7405:2008+A1:2013 - Dentistry. Evaluation of biocompatibility of medical devices used in dentistry; 2009.

27. Benjamin EM, P. Bourdeau E, Somers GM, Richardson, Hickman. aJR. Short-term toxicity tests for non-genotoxic effects: John Wiley \& Sons, Ltd.; 1991.

28. Boukamp P, Petrussevska RT, Breitkreutz D, Hornung J, Markham A, Fusenig NE. Normal keratinization in a spontaneously immortalized aneuploid human keratinocyte cell line. Journal of Cell Biology 1988;106(3):761-71.

29. Dickson MA, Hahn WC, Ino Y, et al. Human Keratinocytes That Express hTERT and Also Bypass a p16INK4a-Enforced Mechanism That Limits Life Span Become Immortal yet 
Retain Normal Growth and Differentiation Characteristics. Molecular and Cellular Biology 2000;20(4):1436-47.

30. Moharamzadeh K, Van Noort R, Brook IM, Scutt AM. Cytotoxicity of resin monomers on human gingival fibroblasts and HaCaT keratinocytes. Dental Materials 2007;23(1):40-44.

31. John FM, Keith AW, Christopher AL, Dawn B. Pharmaceutical Compounding and Dispensing. 2 ed. TJ International, Padstow, Cornwall, UK: Pharmaceutical Press; 2010.

32. Corral Nuñez CM, Bosomworth HJ, Field C, Whitworth JM, Valentine RA. Biodentine and Mineral Trioxide Aggregate Induce Similar Cellular Responses in a Fibroblast Cell Line. Journal of Endodontics 2014;40(3):406-11.

33. Lewis MAO, Sankar V, De Laat A, Benoliel R. Management of neuropathic orofacial pain. Oral Surgery, Oral Medicine, Oral Pathology, Oral Radiology, and Endodontology 2007;103, Supplement(0):S32.e1-S32.e24.

34. Sudoh Y, Cahoon EE, Gerner P, Wang GK. Tricyclic antidepressants as long-acting local anesthetics. Pain 2003;103(1-2):49-55.

35. Phillips WA, Johnson S, Nguyen M, O'Lenic K, Pokorney T, Randolph S. Compounding is Confounding Workers' Compensation. CompPharma 2015 [cited 2015 April 2015];

Available from: www.comppharma.com/CompoundDrugResearch.pdf

36. FDA. Compounding and the FDA: Questions and Answers. 2015 [cited 2015 6th of July]; Available from:

http://www.fda.gov/Drugs/GuidanceComplianceRegulatorylnformation/PharmacyCompoun ding/ucm339764.htm

37. FDA. The Drug Development Process/Step 2: Preclinical Research. The Drug Development Process 2015 [cited 11/05/2015]; Available from:

http://www.fda.gov/ForPatients/Approvals/Drugs/ucm405658.htm

38. Ahuja V, Sharma S. Drug safety testing paradigm, current progress and future challenges: An overview. Journal of Applied Toxicology 2014;34(6):576-94.

39. Cordero MD, Moreno-Fernández AM, Gomez-Skarmeta JL, et al. Coenzyme Q10 and alpha-tocopherol protect against amitriptyline toxicity. Toxicology and Applied Pharmacology 2009;235(3):329-37.

40. Gao X-M, Margolis RL, Leeds P, Hough C, Post RM, Chuang D-M. Carbamazepine induction of apoptosis in cultured cerebellar neurons: effects ofN-methyl-d-aspartate, aurintricarboxylic acid and cycloheximide. Brain Research 1995;703(1-2):63-71.

41. Araújo IM, Ambrósio AF, Leal EC, et al. Neurotoxicity Induced by Antiepileptic Drugs in Cultured Hippocampal Neurons: A Comparative Study between Carbamazepine, Oxcarbazepine, and Two New Putative Antiepileptic Drugs, BIA 2-024 and BIA 2-093. Epilepsia 2004;45(12):1498-505.

42. Pavone A, Cardile V. An In Vitro Study of New Antiepileptic Drugs and Astrocytes. Epilepsia 2003;44(SUPPL. 10):34-39. 
Table 1: Laboratory and equivalent clinical concentrations of Amitriptyline (AMI), Carbamazepine (CBZ) and Gabapentin (GAB).

\begin{tabular}{|l|l|l|l|l|}
\hline \multirow{2}{*}{$\begin{array}{l}\text { Neuromodulatory } \\
\text { medications }\end{array}$} & \multicolumn{2}{|l|}{ Low concentration } & \multicolumn{2}{l|}{ High concentration } \\
\cline { 2 - 5 } & $\begin{array}{l}\text { Laboratory } \\
\text { concentration } \\
(\mu \mathrm{M})\end{array}$ & $\begin{array}{l}\text { Equivalent } \\
\text { clinical } \\
\text { concentration } \\
(\%)\end{array}$ & $\begin{array}{l}\text { Laboratory } \\
\text { concentration } \\
(\mathrm{mM})\end{array}$ & $\begin{array}{l}\text { Equivalent } \\
\text { clinical } \\
\text { concentration } \\
(\%)\end{array}$ \\
\hline AMI & 200 & 0.006 & 1.8 & 0.05 \\
\hline CBZ & 100 & 0.002 & 1.7 & 0.04 \\
\hline GAB & 150 & 0.002 & 5.54 & 0.09 \\
\hline
\end{tabular}


Figure Legends:

Figure 1: Viability of HaCat cells exposed to Amitriptyline (AMI), Carbamazepine (CBZ) and Gabapentin (GAB), measured using alamarBlue ${ }^{\circledR}$. Mean values \pm SEM $(n=8)$ are shown for each experiment. Compared with untreated control cells (black dotted line) by one-way ANOVA followed by Bonferroni's post hoc test, * $p<0.05$.

Figure 2: Viability of OKF6-TERT1 cells exposed to Amitriptyline (AMI), Carbamazepine (CBZ) and Gabapentin (GAB), measured using alamarBlue ${ }^{\circledR}$. Mean values + SEM $(n=8)$ are shown for each experiment. Compared with untreated control cells (black dotted line) by one-way ANOVA followed by Bonferroni's post hoc test, ${ }^{*} p<0.05$.

Figure 3: Viability of HaCat cells exposed to Amitriptyline (AMI), Carbamazepine (CBZ) and Gabapentin (GAB) at $30 \mathrm{~min}$ and $24 \mathrm{~h}$ time points, measured using alamarBlue ${ }^{\circledR}$. Mean values \pm SEM $(n=6)$ are shown for each experiment. Compared with untreated control cells (black dotted line) by one-way ANOVA followed by Bonferroni's post hoc test, ${ }^{*} p<0.05$.

Figure 4: Viability of OKF6-TERT1 cells exposed to Amitriptyline (AMI), Carbamazepine (CBZ) and Gabapentin (GAB) at $30 \mathrm{~min}$ and $24 \mathrm{~h}$ time points, measured using alamarBlue ${ }^{\circledR}$. Mean values + SEM $(n=6)$ are shown for each experiment. Compared with untreated control cells (black dotted line) by one-way ANOVA followed by Bonferroni's post hoc test, ${ }^{*} p<0.05$.

Figure 5: SEM images at $100 \mathrm{X}$ magnification of OKF6-TERT1 and HaCat cells after $30 \mathrm{~min}$ exposure to NMs at concentrations determined by HPLC. 